\title{
Evaluation of Hybrid Seeds of Three-Way and Single Cross for Grain Number and Weight in Bread and Durum Wheat
}

\author{
Mustafa Yıldırım $^{1 *}$, Mustafa Çakmak ${ }^{2}$ \\ ${ }^{1}$ Faculty of Agriculture, Kahramanmaraş Sütçü Imam University, 46040 Kahramanmaraş, Turkey \\ ${ }^{2}$ Transitional Zone Agricultural Research Institute, 26200 Eskişehir, Turkey
}

\section{A R T I C LE IN F O}

\section{Research Article}

Received 09 August 2017

Accepted 28 November 2017

Keywords:

Hybrid seed

Single cross

Three-way cross

Wheat

Grain number

*Corresponding Author:

E-mail: m.yildirim@ksu.edu.tr

\begin{abstract}
A B S T R A C T
The hybrid seeds obtained by crossing in wheats should be heavier and a greater number of grains per combination because of more variation and to created powerful plants for next year generations. Therefore, this study was conducted during the winter growing season of 2005-2006 in Transitional Zone Agricultural Research Institute in Eskişehir and to determine the hybrid seeds of single cross and three-way cross compared to each other for 10-grains weight (TGW) and grain number per combination (GC) in separately bread wheat and durum wheat. $224 \mathrm{~F}_{1}$ s for single cross and $326 \mathrm{~F}_{1}$ for three-way cross in bread wheat and $56 \mathrm{~F}_{1} \mathrm{~s}$ for single cross and $66 \mathrm{~F}_{1} \mathrm{~s}$ for three-way cross in durum wheat were produced. According to results, GC and TGW in bread wheats were higher values than durum wheats both in single cross and three-way cross. The GC values in three-way cross had higher variation $(68.9 \%$ ) compared the others. The separately mean of GC and TGW of hybrids in single cross both in bread and durum wheat were lower than the means of hybrids in three-way cross (with ratios of $32 \%$ and $16.7 \%$, respectively). In brief: threeway cross had more performance for studied traits in wheat hybrids compared to single cross. The reason of such an outcome can be demonstrated in the future by genetic studies.
\end{abstract}

DOI: https://doi.org/10.24925/turjaf.v6i1.22-27.1464

\section{Introduction}

Wheat (Triticum L.) is an annual plant that belongs to the grass family Poaceae (Haider, 2010) and the selfpollinating is appeared in wheat, but cross-pollinating occurs possible between genotypes at variable rates (Jain, 1975). If a wheat genotype is well-adapted for an environment, self-pollination in wheat helps to keep this trait stable. To cross between two self-pollinated genotypes can give a high rate of success for the desired trait due to purity of genotype. All of genotypes don't show the same ability in crosses (Weatherspoon, 1970; Loureiro et al., 2011). Because pollen receptivity of stigma of a genotype is dependent on environmental conditions and genetically structure of genotypes (De Vries, 1971).

Single cross and three-way cross are especially used by breeders in wheat breeding programme. Single cross is the crossing of a genotype or pure-line with another genotype or pure-line (Gunter and Weber, 1986). The three-way cross $[(\mathrm{AxB}) \mathrm{xC}]$ is the crossing between an $\mathrm{F}_{1}$ (single cross) (AxB) as female parent and a genotype or pure-line (C) as male parent (Darbeshwar, 2000).
Why are the $F_{1}$ s of three-way cross more stable and useful than $\mathrm{F}_{1} \mathrm{~s}$ of single cross for hybrid seed production? Not only three-way crosses were more useful than single crosses (Schoonhoven and Voysest, 1991) because threeway crosses can be more stable in performance than single crosses under variable environment conditions (Hopokstra and Ross, 1982), but three-way cross also can collected some desirable traits from three genotypes into a genotype. These reasons can probably dependent on grain size and weight of three-way hybrid seeds. The smaller and less weight seeds in cereals are undesirable because they create weak and powerless plant. The size and weight of hybrid seeds are lower than normal seeds of genotypes or pure-lines. The rate of seedlings growth or seedling vigor in cereals is controlled by seed size, seed contents and genotype (Ries and Everson, 1973). Breeders want to get hybrid seeds which are big size and heavy grains from crossing because of good germination (Larsen and Andreasen, 2004). The number and weight of the hybrid seeds per combination not only may vary species to species but this variation also depends on the type of crossing even within the same species. Therefore, 
this trial was established to determine the rates of this change. The objective of this trial was to determine the differences between single cross and three-way cross for grain number per combination and 10-grain weight both in bread wheat and durum wheat.

\section{Materials and methods}

\section{Experimental Location}

This study was conducted during the 2005-2006 growing season in Transitional Zone Agricultural Research Institute in Eskişehir (39 $46^{\prime} \mathrm{N}$ and $30^{\circ} 32^{\prime} \mathrm{E}$ ), Turkey. Soil analysis indicated the soil in the experimental field to be loamy, slightly alkaline, and medium in terms of organic matter and calcium, poor in terms of available phosphorus and rich in terms of available potassium. The total rainfall of 2005-06 growing season $(242.8 \mathrm{~mm})$ was lower than long-term rainfall (326.9 mm). In 2005-06 growing season, precipitation in April and May were 35.4 and $43.1 \mathrm{~mm}$, respectively. Precipitations in April and May are very important in terms of fertilization and grain filling. Therefore, irrigation was made two times in April and May by sprinkler.

\section{Plant Materials}

In this study, 290 pure-lines and $326 \mathrm{~F}_{1}$ hybrids of bread wheat and 84 pure-lines and $66 \mathrm{~F}_{1}$ hybrids of durum wheat were used as parents. The single crosses were produced to cross among pure-lines. The three-way crosses were produced to cross between $F_{1} s$ and purelines. For three-way crosses, $\mathrm{F}_{1} \mathrm{~s}$ were used as female and pure-lines were used as male parents. In total, $224 \mathrm{~F}_{1} \mathrm{~s}$ for single cross and 326 for three-way cross were produced in bread wheat, while $56 \mathrm{~F}_{1} \mathrm{~s}$ for single cross and 66 for topcross were produced in durum wheat.

\section{Experimental Design}

The $F_{1}$ hybrids and pure-lines as parental materials were sown at three different day basis in 2005; first was $14^{\text {th }}$ October, second was $28^{\text {th }}$ October and third was $12^{\text {st }}$ November, because they had different flowering dates. Every sowing date was immediately irrigated after sowing by sprinkler to obtain early germination. The plot of each material for every sowing date had three rows with 1-m long and $20-\mathrm{cm}$ row spaces. Fertilizer was applied DAP (150 kg N ha-1) before planting and $\mathrm{AN}$ (200 kg $\mathrm{P}_{2} \mathrm{O}_{5} \mathrm{ha}^{-}$ $\left.{ }^{1}\right)$ at the shooting stage (Zadoks, 1974). Weed-control was performed by herbicide application at the main shoot stage (Zadoks, 1974), because crop plants are more susceptible to herbicide at the early growth stage (Qasem, 2011).

\section{Emasculation and Crossing}

In crossing, three spikes as female per combination and three spikes as male per female spike were used. Crosses for single-cross were made between two pure lines $\left(\mathrm{AxB}=\mathrm{F}_{1}\right)$ and crosses for three-way cross were made between a single-cross $\left(\mathrm{F}_{1}\right)$ and a pure line, $\mathrm{C}$, as the male parent to give the $\mathrm{F}_{1} \mathrm{xC}[(\mathrm{AxB}) \mathrm{xC}]$ pedigree. The emasculations and crosses were made by 20 professional employees during two weeks who work for National Wheat Breeding Programme (NWBP) and International
Winter Wheat Improvement Project (IWWIP) in Turkey. Three female spikes per combination were selected before three or four days than expected flowering. Two spikelets from both bottom and top of female spike were removed, because they were younger than other spikelets (Yildirim, 2005). The center florets of each spikelet of female spike were pulled out and two florets stayed on each spikelet. The glume, lemma and palea just above the top of the stigma of each spikelet were cut with scissors. The three anthers were carefully removed from each floret with forceps. The female spike was covered with paper bag later to emasculate all of spikelets. The emasculated female spike within paper bag was kept until crossing day about 2 or 3 days. Three male spikes per female spike were chosen from healthy meal plant. They were ready to flower which to have one or two anthers may show. The lemma and palea were clipped just above the anthers. The peduncle of male spike in wet soil under sun light was placed and protected from the wind. Crossing was made by twirl method when anthers started to come out from florets of male spike (Villereal, 2000). Fallowing crossing, the edge of paper bag was again closed. The pollinated spikes were kept until harvest in the field.

\section{Collecting Data and Statistical Analysis}

The three female spikes per combination were harvested including in paper bag at the harvest ripe according to Zadoks-92 (Zadoks, 1985) and their grains were blended all together. They were counted for grain number per combination (GC). The 10-kernel weight was calculated using the following formula;

Where;

$$
T G W_{i}=\frac{G W_{i} \times 10}{G C_{i}}
$$

$\mathrm{TGW}_{\mathrm{i}}$ : 10-kernel weight $(\mathrm{g})$

$\mathrm{GW}_{\mathrm{i}}$ : Total grain weight per combination $(\mathrm{g})$

$\mathrm{GC}_{\mathrm{i}} \quad$ : Total grain number per combination

The collected data of two traits both in single and three-way crosses were analysed for distribution and their graphs were drawn using with the JMP 5.0.1a. (1989 2002 SAS Institute Inc., NC, USA).

\section{Results}

Single and Three-Way Crosses in Bread Wheat (Triticum Aestivum L.)

The coefficients of variations of distributions were $49.84 \%$ for grain number per combination (GC) and $30.27 \%$ for 10 -grain weight (TGW) in single cross, and $44.67 \%$ for GC and $23.87 \%$ for TGW in three-way cross (Table 1). Standard errors were both in single and threeway cross (14.394 and 18.952, respectively) for GC higher than both in single and three-way cross $(0.075$ and 0.071 , respectively) for TGW. Maximum value, minimum value, upper mean, lower mean and guartile (level of $75 \%$ and $25 \%$ ) were observed lower in single cross than in three-way cross both for two traits. The relationship was observed between TGW and GC both in single cross and in three-way cross in bread wheat $(\mathrm{P}>0.05)$.

The separately means of GC and TGW in single cross were 28.88 grains/combination and $0.25 \mathrm{~g} 10$-grain $^{-1}$, respectively, and in three-way cross were 42.46 
grains/combination and $0.30 \mathrm{~g} 10$-grain $^{-1}$, respectively (Figure 1 and Table 1). Not only the mean of GC in threeway cross was $32 \%$ higher than in single cross but higher observation also was detected for TGW (16.7\%).

According to histogram curves, there were normal distributions for TGW in single and three-way crosses (Figure 2). The sum of frequencies in single crosses for TGW was 224 and sum of frequencies in three-way crosses for TGW was 326. The histogram column numbers of frequencies for TGW were in 7 for single cross and in 10 for three-way cross. The TGW of single crosses ranged from 0.07 to $0.48 \mathrm{~g} 10$-grain ${ }^{-1}$, while TGWs of three-way crosses ranged from 0.06 to $0.53 \mathrm{~g}$ 10 -grain ${ }^{-1}$. The largest concentration of TGW was in the 0.2 up to $0.25 \mathrm{~g} 10$-grain $^{-1}$ for single cross and was 0.25 up to $0.3 \mathrm{~g} 10$-grain $^{-1}$ for three-way cross. The TGW were concentrated between 0.2 and $0.35 \mathrm{~g} 10$-grain $^{-1}$ for single cross and were concentrated between 0.25 and $0.35 \mathrm{~g} 10$ grain $^{-1}$ for three-way cross. A total of $159(71 \%)$ frequencies between those intervals for single cross was good level within range and $188(83.9 \%)$ frequencies for three-way cross was good level within range. Not only 3 of the frequencies were observed over the $0.45 \mathrm{~g} \mathrm{10 \text {-grain }}$ ${ }^{1}$, but also 3 were observed for less than $0.1 \mathrm{~g} 10$-grain $^{-1}$.

The frequency columns for GC were 13 in single cross and 17 in three-way cross (Figure 2). According to histogram curves, there was a multimodal distribution for single cross, while there was a comb distribution for three-way cross. The comb distribution was nearly similar to normal distribution. In the 35 up to 40 class and 45 up to 50 classes, lower frequencies impaired the normal distribution. The TGWs ranged from 4 to 64 for single cross and from 4 to 84 for three-way cross. The largest concentrations of GC were in the 10 up to 15 for single cross and were in the 40 up to 45 for three-way cross. 206 (92\%) frequencies for single cross and 256 (78.5\%) frequencies for three-way cross between given intervals were good levels within this range.

\section{Single and Three-Way Crosses in Durum Wheat} (Triticum Durum Desf.)

The coefficients of variations of distributions were $68.91 \%$ and $29.62 \%$ in single cross for GC and TGW, respectively and $43.86 \%$ and $27.94 \%$ in three-way cross for GC and TGW, respectively (Table 2). Standard errors were both in single and three-way cross (12.688 and 17.332, respectively) for GC higher than both in single and three-way cross $(0.070$ and 0.073 , respectively) for TGW. The values of maximum value, minimum value, upper mean, lower mean and guartile (level of $75 \%$ and $25 \%$ ) were observed lower in single cross than in threeway cross for both two treatments. There was relationship between TGW and GC both in single cross and three-way cross in durum wheat $(\mathrm{P}>0.05)$.

Table 1 Distribution analysis of GC and TGW in separately for single-crosses and top-crosses in bread wheat.

\begin{tabular}{l|rrrr}
\hline \multirow{2}{*}{ Characteristics } & \multicolumn{2}{|c}{ Single cross } & \multicolumn{2}{c}{ Top cross } \\
\cline { 2 - 5 } & \multicolumn{1}{c|}{ GC } & TGW & GC & TGW \\
\hline DF & 223 & 223 & 325 & 325 \\
Std. err. & 14.394 & 0.075 & 18.952 & 0.071 \\
Std err. mean & 0.962 & 0.005 & 1.050 & 0.004 \\
Variance & 207.192 & 0.006 & 359.168 & 0.005 \\
Mean & 28.88 & 0.25 & 42.46 & 0.30 \\
Max. value & 64 & 0.48 & 84 & 0.53 \\
Min. value & 4 & 0.07 & 4 & 0.06 \\
Upper mean (95\%) & 30.78 & 0.26 & 44.49 & 0.31 \\
Lower mean (95\%) & 26.98 & 0.24 & 40.36 & 0.29 \\
Guartile (75\%) & 40.00 & 0.29 & 56.25 & 0.34 \\
Guartile (25\%) & 15.00 & 0.21 & 29.00 & 0.26 \\
CV (\%) & 49.84 & 30.27 & 44.67 & 23.87 \\
Correlation & & & & $0.078^{*}$ \\
\hline
\end{tabular}

*Significant at the 0.05
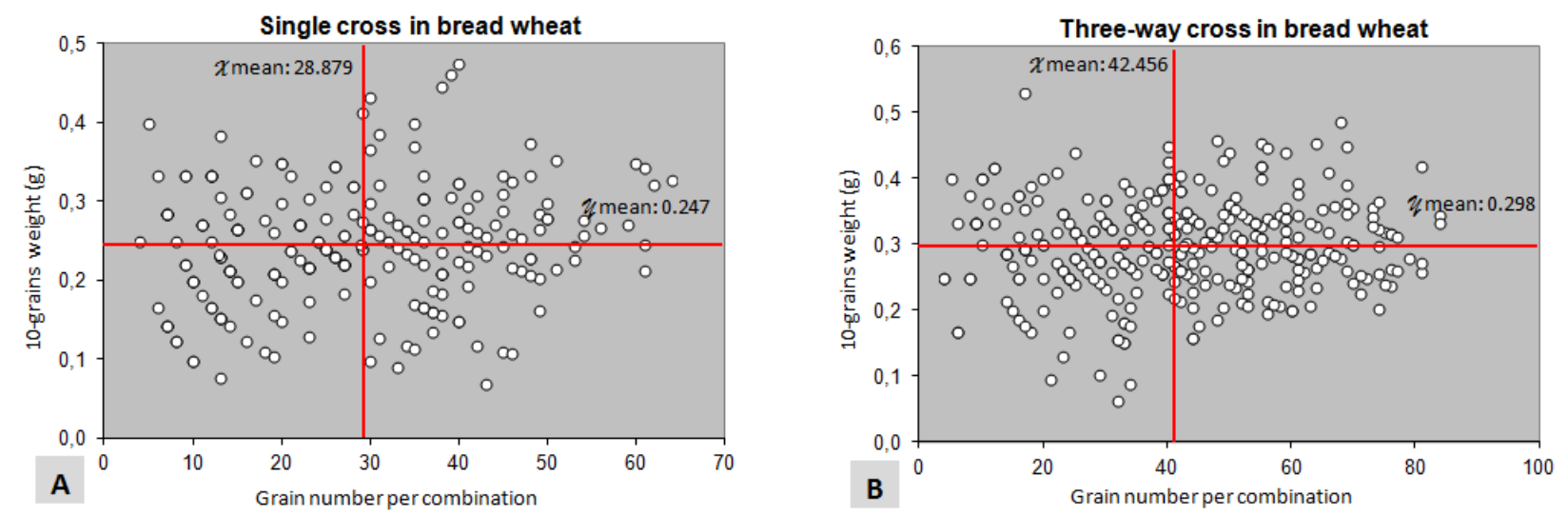

Figure 1 The distributions of GC and TGW in bread wheat for A-single cross and B-three-way cross 

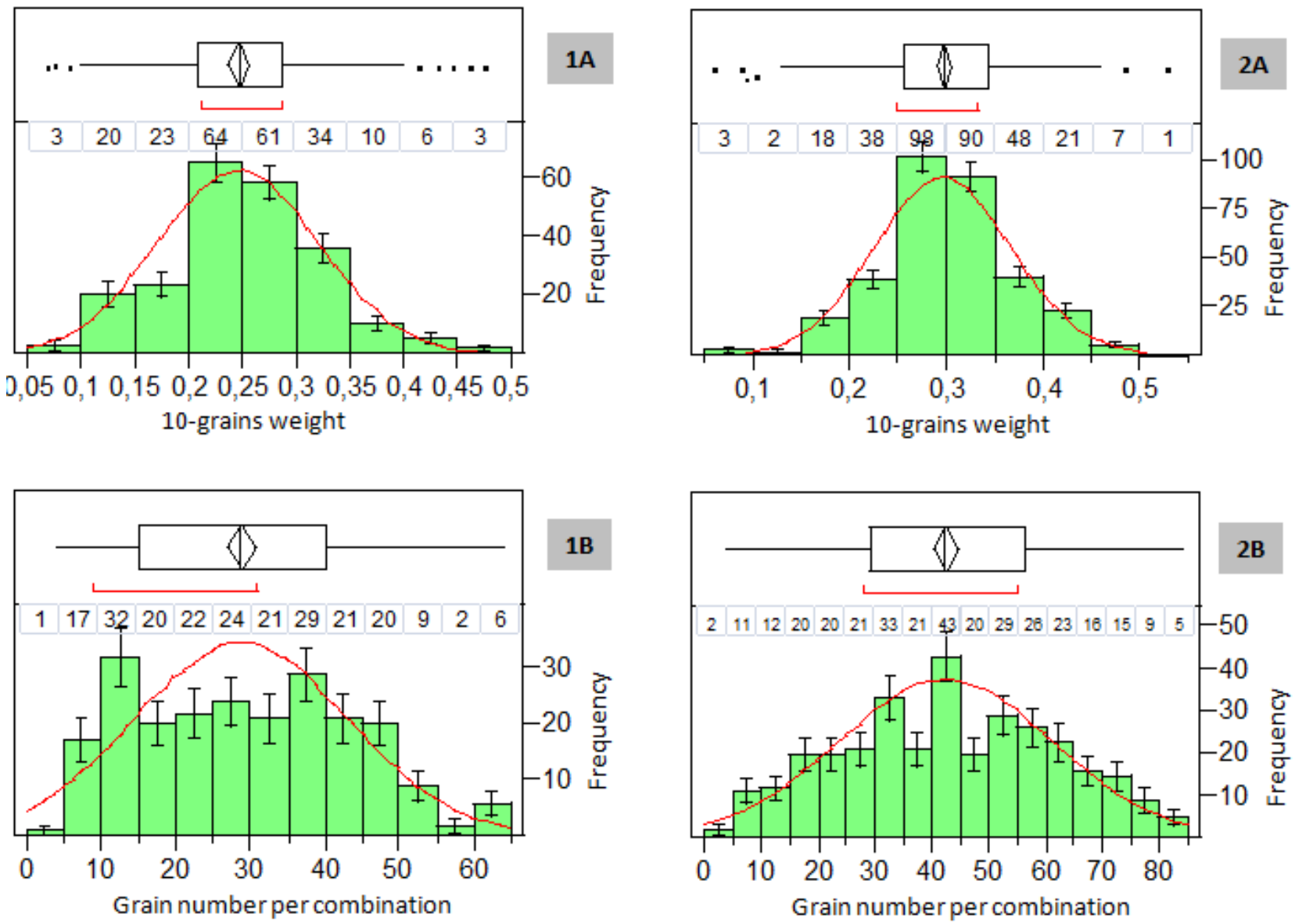

Figure 2 In bread wheat; the frequency distributions of TGW for (1A) single cross and (2A) three-way cross, and of GC for (1B) single cross and (2B) three-way cross
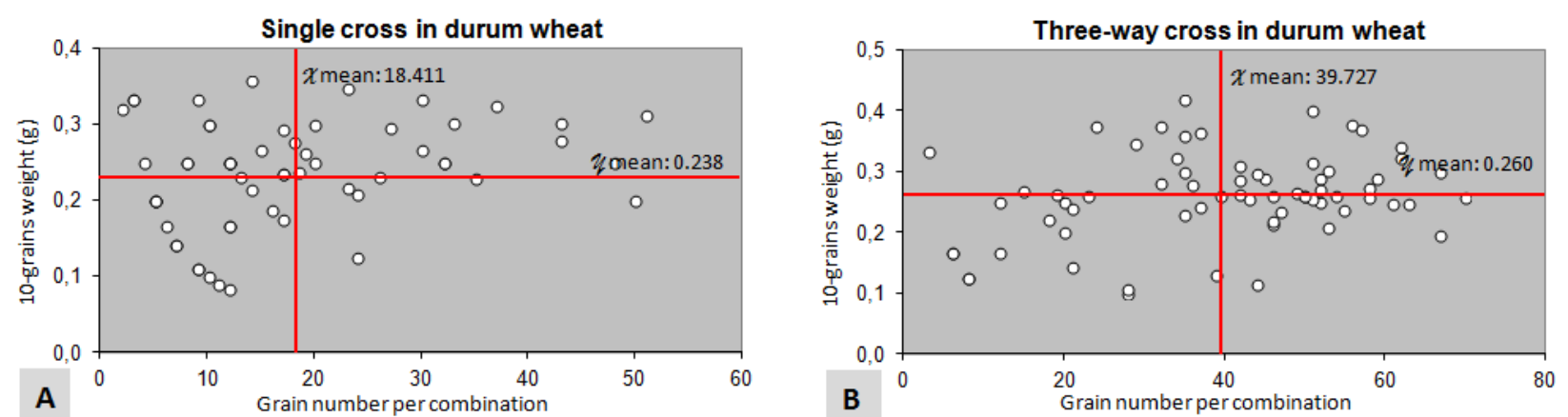

Figure 3 The distributions of GC and TGW in durum wheat for A-single cross and B-three-way cross

The separately means of GC and TGW in single cross were 18.41 grains/combination and $0.24 \mathrm{~g}$, respectively, and were 39.73 grains/combination and $0.26 \mathrm{~g}$, respectively in three-way cross (Figure 3 and Table 2). Not only the mean of grains per combination in three-way cross was $53.7 \%$ higher than single cross but the higher observation also was detected for 10-grain weight (7.7\%).

There were semi-normal distributions to look like a normal distribution for TGW in both single and three-way crosses (Figure 4). In the 0.175 up to 0.2 class, 0.225 up to 0.25 class and 0.275 up to 0.3 class, lower frequencies impaired the normal distribution for TGW in single cross, while the lower frequencies in two column between 0.15 and 0.2 classes impaired the normal distribution for TGW in three-way cross. The sum of frequencies of single crosses for TGW was 56 and sum of frequencies of three- way crosses for 10-grain weight was 66 . The histogram column numbers of frequencies for TGW were in 12 for single cross and in 13 for three-way cross. The 10 TGWs of single crosses ranged from 0.08 to $0.36 \mathrm{~g} 10$-grain $^{-1}$, while TGW of three-way crosses ranged from 0.1 to 0.42 g 10-grain ${ }^{-1}$. The largest concentration of TGW both in single and three-way crosses was in the 0.25 up to $0.275 \mathrm{~g}$ 10 -grain ${ }^{-1}$. The TGW were concentrated between 0.2 and $0.35 \mathrm{~g} 10$-grain $^{-1}$ for single cross and were concentrated

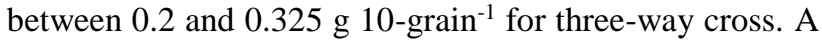
total of $42(75 \%)$ frequencies between those intervals for single cross was good level within range and 44 (66.7\%) frequencies for three-way cross was good level within range. Not only 1 of the frequencies was observed over the $0.35 \mathrm{~g} 10$-grain $^{-1}$, but also 2 were observed for less than 0.1 g 10 -grain ${ }^{-1}$. 
Table 2 Distribution analysis of GC and TGW in separately for single-crosses and top-crosses in durum wheat.

\begin{tabular}{l|rrrr}
\hline \multirow{2}{*}{\multicolumn{1}{c|}{ Characteristics }} & \multicolumn{3}{c}{ Single cross } & \multicolumn{2}{c}{ Top cross } \\
\cline { 2 - 5 } & \multicolumn{1}{c}{ GC } & TGW & GC & TGW \\
\hline DF & 55 & 55 & 65 & 65 \\
Std. err. & 12.688 & 0.070 & 17.332 & 0.073 \\
Std err. mean & 1.695 & 0.009 & 2.133 & 0.009 \\
Variance & 160.974 & 0.005 & 300.407 & 0.005 \\
Mean & 18.41 & 0.24 & 39.73 & 0.26 \\
Max. value & 51 & 0.36 & 70 & 0.42 \\
Min. value & 2 & 0.08 & 3 & 0.10 \\
Upper mean (95\%) & 21.81 & 0.26 & 73.78 & 0.28 \\
Lower mean (95\%) & 15.02 & 0.22 & 35.25 & 0.24 \\
Guartile (75\%) & 25.50 & 0.29 & 52.25 & 0.30 \\
Guartile (25\%) & 9.00 & 0.20 & 27.00 & 0.23 \\
CV (\%) & 68.91 & 29.62 & 43.86 & 27.94 \\
Correlation & & $0.252 *$ & & $0.307 *$ \\
\hline
\end{tabular}

*Significant at the 0.05
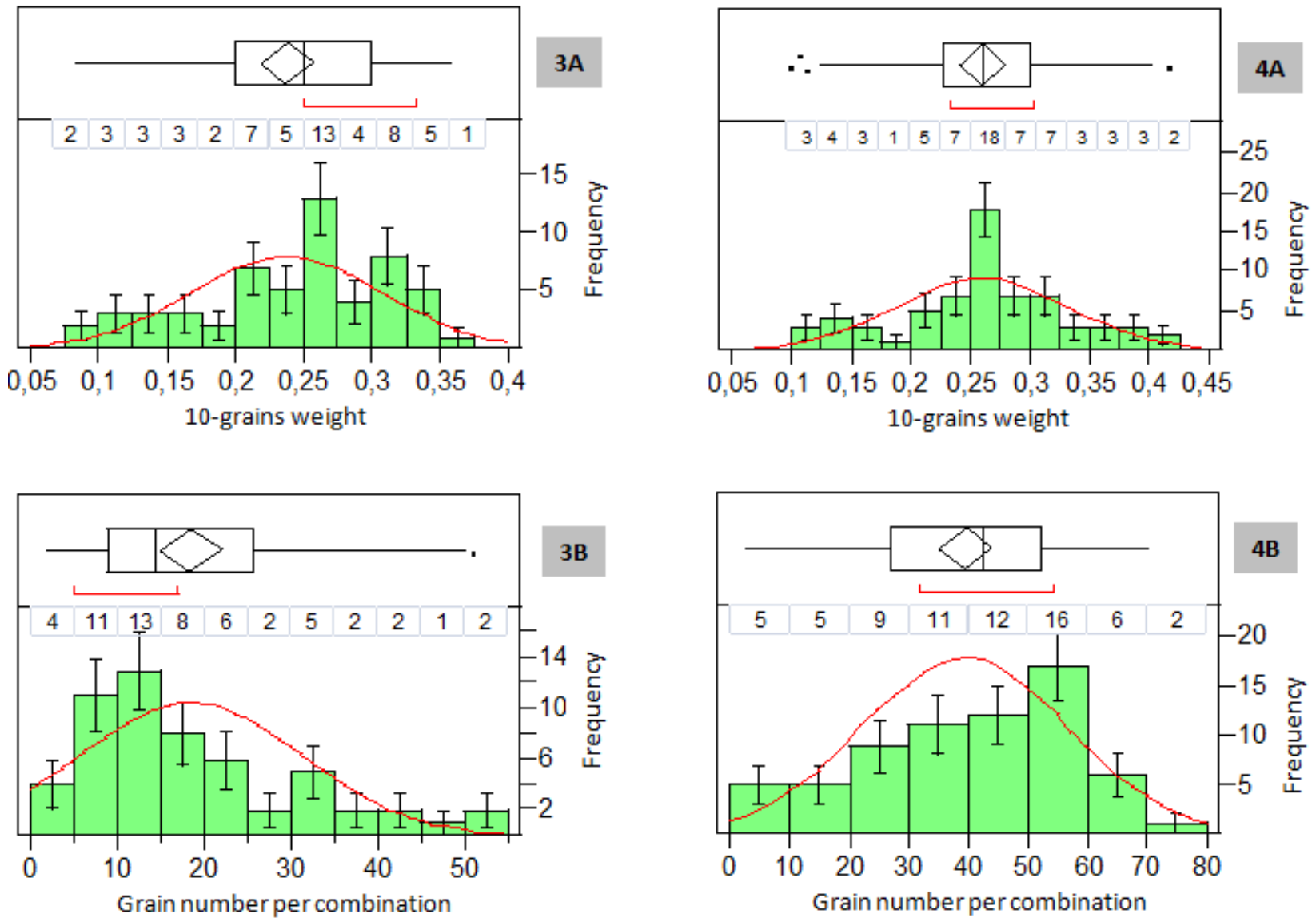

Figure 4 In durum wheat; the frequency distributions of TGW for $(3 \mathrm{~A})$ single cross and (4A) three-way cross, and of GC for (3B) single cross and (4B) three-way cross

The frequency columns for GC were 11 in single cross and 8 in three-way cross (Figure 4). According to histogram curves, they showed asymmetrical image that there was a left-skewed distribution for single cross, while there was a right-skewed distribution for three-way cross. The GCs ranged from 2 to 51 for single cross and from 3 to 70 for three-way cross. The largest concentrations of $\mathrm{GC}$ were in the 5 up to 25 for single cross and were in the 20 up to 60 for three-way cross. $38(67.9 \%)$ frequencies for single cross and $48(72.7 \%)$ frequencies for three-way cross between given intervals were good levels within this range.

\section{Discussion}

The GC in bread wheat had higher values than durum wheat both in single cross and three-way cross. The mean of GC in single cross (28.88 grains/combination) was $32 \%$ lower than three-way cross (42.46 grains/combination) in bread wheat. In addition, the mean of GC in single cross (18.41 grains/combination) was $53.7 \%$ lower than three-way cross $(39.73$ grains/combination) in durum wheat. The maximum value for GC in three-way cross was $23.8 \%$ higher than single cross in bread wheat. The maximum value for GC in 
three-way cross was $27.1 \%$ higher than single cross in durum wheat. The upper mean and lower mean in threeway were observed higher than single cross; in bread wheat $(30.8 \%$ and $33.2 \%)$ and in durum wheat $(70.4 \%$ and $57.4 \%$ ), respectively.

The mean of TGW in single cross $\left(0.25 \mathrm{~g} 10\right.$-grain $\left.^{-1}\right)$ was $16.7 \%$ lower than three-way cross $\left(0.3 \mathrm{~g} 10\right.$-grain $\left.^{-1}\right)$ in bread wheat. Similarly, the mean of TGW in single cross $\left(0.24 \mathrm{~g} 10\right.$-grain $\left.^{-1}\right)$ was $7.7 \%$ lower than three-way

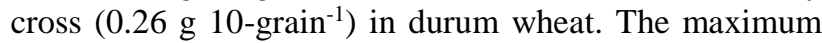
value for TGW in three-way cross was $9.4 \%$ higher than single cross in bread wheat. In addition, the maximum value for TGW in three-way cross was $14.3 \%$ higher than single cross in durum wheat. The upper mean and lower mean in three-way cross were observed higher than single cross; in bread wheat $(16.1 \%$ and $17.2 \%)$ and in durum wheat $(7.1 \%$ and $8.3 \%)$, respectively.

According to results, the bread wheat had higher GC and TGW compared to durum wheat both in single cross and three-way cross. The findings separately both in bread wheat and durum wheat showed that three-way cross had higher GC than single cross. Similarly, the mean of TGW in three-way cross was higher than single cross both in bread wheat and durum wheat. These results might be due to three parents because chromosomal structures of hybrid seeds of three-way cross are composed of $\mathrm{A}, \mathrm{B}$ and $\mathrm{C}$ parents (Their ratios in $\mathrm{F}_{1}$ are $25 \%, 25 \%$ and $\% 50$, respectively). The further genetic studies could explain that why the three-way cross has higher values for GC and TGW than single cross.

\section{Acknowledgements}

This study had been supported financially by the National Wheat Breeding Programme in Transitional Zone Agricultural Research Institute in Eskişehir, Turkey. The authors thank the institute and its members for their financial support and gentleness.

\section{References}

Darbeshwar R. 2000. Plant breeding analysis and exploitation of variation. Pangbourne, UK: Alpha Sci Int Page 446.

De Vries AP. 1971. Flowering biology of wheat particularly in view of hybrid seed production- a review. Euphytica 20: 152-170.

Gunter W, Weber E. 1986. Quantitative genetics and selection in plant breeding. Berlin: W. de Gruyter. Page 257.

Haider N. 2010. Evidence for the origin of the B genome of bread wheat based on chloroplast DNA. Turk J Agric For 36 (2012) 13-25.

Hopokstra GH, Ross WM. 1982. Comparison of $F_{1}$ s and inbreds as female parents for hybrid sorghum seed production. Crop Sci 22: $145-150$.

Jain SK. 1975. Population structure and the effects of breeding system. In: Frankel, O.H. and J.G. Hawkes (Eds.), Crop Genetic Resources for Today and Tomorrow, Cambridge, pp. 15-36.

Larsen SU, Andreasen C. 2004. Light and heavy turfgrass seeds differ in germination percentage and mean germination thermal time. Crop Sci 44: 1710 -1720.

Loureiro I, Escorial C, Santin I, Chueca C. 2011. Pollen Mediated Gene Flow in GM Crops: the Use of Herbicides as Markers for Detection. The Case of Wheat, Herbicides, Theory and Applications by Prof. Marcelo Larramendy (Ed.), part: 12, p. 225-236.

Qasem JR. 2011. Herbicides Applications: Problems and Considerations. Herbicides and Environment 32: 644-646.

Ries SK, Everson EH. 1973. Protein content and seed size relationship with seedling vigour of wheat cultures. Agronomy $\mathbf{J}$ 65: 884-886.

Schoonhoven AV, Voysest O. 1991. Common Beans: Research for Crop Improvement. CAB International with CIAT, U.K., p. 411-413.

Villereal R. 2000. Making the crosses in wheat. CIMMYT Wheat Training Notes., p. 119- 122.

Weatherspoon JH. 1970. Comparative yields of single, three-way and double crosses of maize. Crop Sci 10: 157-159.

Yildirim M. 2005. A study on heredity of some agronomical, physiological and quality characteristics in diallel $\mathrm{f}_{1}$ offsprings of selected six bread wheat (Triticum Aestivum L.) cultivars. Natural Science of Cukurova Univ. PhD thesis. Register no: 893: 47-70.

Zadoks JC, Chang TT, Konzak CF. 1974. A Decimal Code for The Growth Stages of Cereals. Weed Res 14: 415-421. 